\title{
Simplified Procedure for Evaluating Soil Liquefaction Characteristics
}

\author{
Shuh-Gi Chern \\ Department of Harbor and River Engineering National Taiwan Ocean University Keelung, Taiwan, R. O. C. \\ Tain-Shyang Chang \\ Department of Harbor and River Engineering National Taiwan Ocean University Keelung, Taiwan, R. O. C.
}

Follow this and additional works at: https://jmstt.ntou.edu.tw/journal

Part of the Civil and Environmental Engineering Commons

\section{Recommended Citation}

Chern, Shuh-Gi and Chang, Tain-Shyang (1995) "Simplified Procedure for Evaluating Soil Liquefaction Characteristics," Journal of Marine Science and Technology. Vol. 3: Iss. 1, Article 6.

DOI: $10.51400 / 2709-6998.2504$

Available at: https://jmstt.ntou.edu.tw/journal/vol3/iss1/6

This Research Article is brought to you for free and open access by Journal of Marine Science and Technology. It has been accepted for inclusion in Journal of Marine Science and Technology by an authorized editor of Journal of Marine Science and Technology. 


\title{
SIMPLIFIED PROCEDURE FOR EVALUATING SOIL LIQUEFACTION CHARACTERISTICS
}

\author{
Shuh-Gi Chern and Tain-Shyang Chang \\ Department of Harbor and River Engineering \\ National Taiwan Ocean University \\ Keelung, Taiwan, R. O.C.
}

Key words: Soil Liquefaction, earthquake, cyclic loading, pore pressure.

\begin{abstract}
The purpose of this paper is to develop a mathematical model for the evaluation of liquefaction characters for soil subjected to earthquake induced cyclic loading. Cyclic triaxial test results are used to develop the basic model. It is then used to evaluate cyclic shear strength $\tau_{R}$, number of cycles required to cause liquefaction $\mathrm{N}_{\ell}$ or failure condition $\mathrm{N}_{f}$, and the generation of excess pore water pressure $u_{\mathrm{g}}$. The development of this model is a great breakthrough for the evaluation of liquefaction characteristics for soils under earthquake loadings.
\end{abstract}

\section{INTRODUCTION}

There are hundreds of recent cases of ground failure and damage to structures due to liquefaction during earthquakes in China, Japan, Yugslavia, Chile, Central America and the United States. During the 1964 earthquake in Niigata, Japan, many structures settled several feet and suffered up to 80 degrees of tilting [15]. The same year, in Valdez, Alaska, extensive flow slides washed entire sections of the waterfront into the sea. In 1979 , liquefaction caused a considerable amount of damage in Imperial Valley, Califronia [21]. Numerous studies have been conducted since then to understand the behavior of cohesionless soil under earthquake loading. Many of these studies have been based on the principle of subjecting representative soil elements to the same loading conditions in the laboratory as they would encounter in the field, and assessing the probable field performance from the resulting behavior of the laboratory test specimens. In the past three decades, there are many laboratory tests developed for measuring liquefaction potential; the cyclic simple shear test [16], the torsional cyclic simple shear test [13], the cyclic triaxial test [6], and large scale shake table tests with precise control on loading and draniage conditions [5]. Numerous methods, theoretical or empirical $[2,9]$, are also developed for estimating liquefaction potential in the field.

For analysis purposes, the evaluation of the in situ dynamic shear strength, $\tau_{R}$, of a saturated cohesionless sand deposit during an earthquake loading is a major step in the prediction of liquefacion potential. $\tau_{R}$ represents the shear resistance that will be mobilized in a sand deposit to resist the applied shear stresses during an earthquake loading. In addition, pore pressure build-up and the number of cycles for soil under a given cyclic shear stress to cause initial liquefaction, $\mathbf{N}_{\ell}$, are also the major concerns for most researchers. However, evaluation of soil liquefaction characteristics requires data on geotechnical details of the soil proflies and cyclic shear stress distribution. Moreover, analytical and testing methods available for performing such evaluation are complex and time consuming.

In this paper, a simplified procedure, based on cyclic test results and statistic analysis is developed to predict liquefaction characteristics for soil under earthquake loading.

\section{PROBLEM DESCRIPTION}

It is well known that earthquake can induce cyclic strsses in foundation soils. Consequently, earthquake indeuce cyclic stresses will cause generation of pore water pressures in soils.

The field stress conditions of a typical element of a saturated sand deposit at a depth $h$ below the level ground surface before the application of cyclic loadings are shown in Fig.1. It is generally assumed that prior to the 


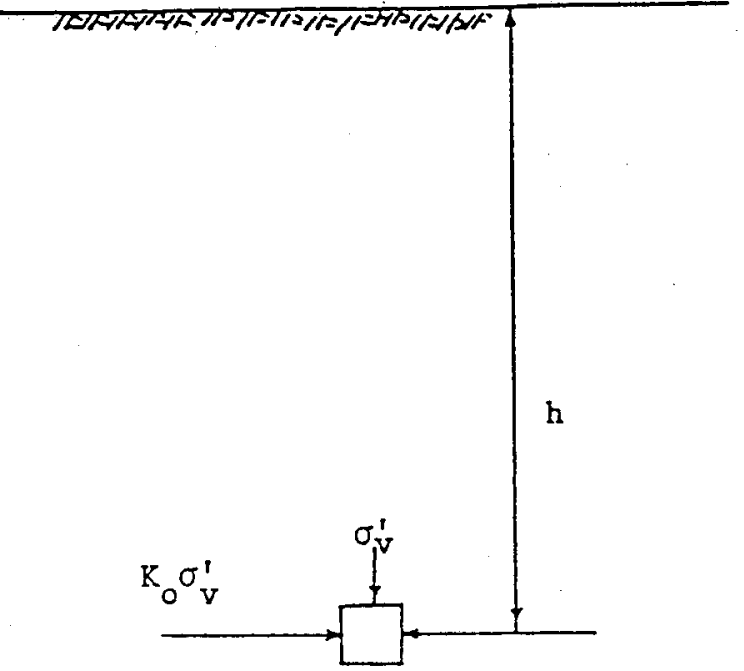

Fig. 1. Stress Condition on a Soil Element before Earthquake Loading.

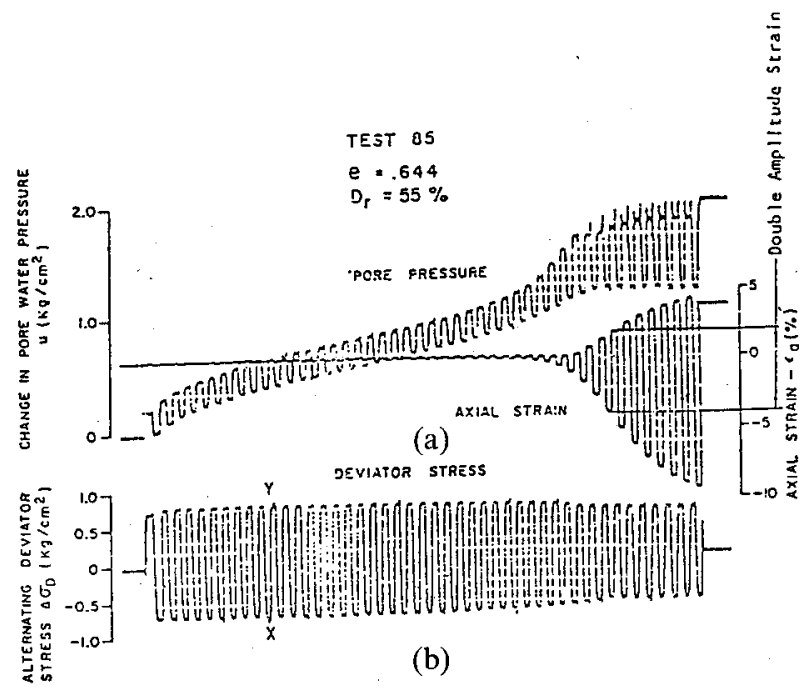

Fig. 3. Foundation Stresses from Level Ground Structure.

earthquake, the soil element is not subjected to any initial static shear stress. Consequently, it is common for the sand deposits with level ground surface be modeled under isotropically consolidated conditions in a laboratory cyclic triaxial test.

Fig. 2 shows the typical cyclic triaxial test results for isotropically consoildated sands. It may be seen that the pore-water pressure continues to increase during the cyclic loading. However, the axial strains are negligible over most of the test range. These strains become appreciable only when the pore pressure appraoches the effective confining pressure. Thereafter, the strain increases very rapidly with the continuing cyclic loading.

The first time pore pressure reaches the effective

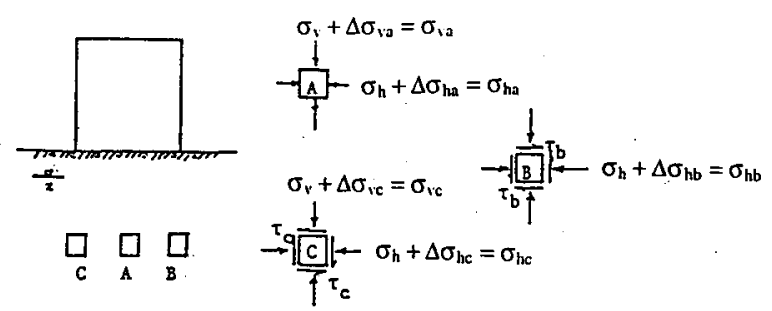

a) Geometry

b) Stresses on Sot1 Elements

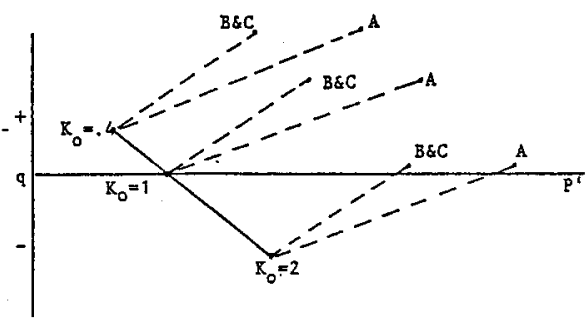

c) Effective Stress Paths for Shallow Elements is

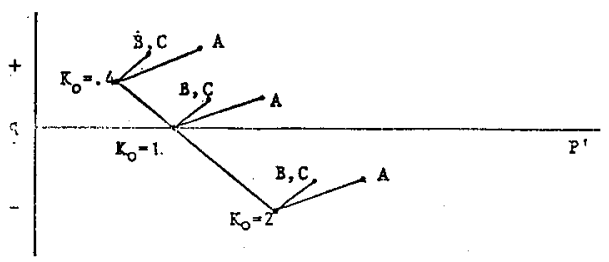

d) Effective Stress Paths for Deep Elements

Fig. 2. Pore Pressure and Axial Strain Development During Cyclic Triaxial Test Conditions [7]

confining pressure, sand has the potential to liquefy. Considering this phenomenon, the mathematical expression for the cyclic shear strength of level ground is usually developed in terms of the magnitude of the applied cyclic shear stress and the load cycles of that stress required to cause initial liquefaction.

An anisotropic stress condition due to the presence of a structure on a level ground is shown in Fig. 3. In this figure, the structure induced stress increments are shown for both shallow and deep soil elements beneath the center and the edges of the structure for three assumed earth pressure coefficients at rest ( $\mathrm{K}_{0}$ values). It can be seen that the shallow elements are affected much more than the deeper ones due to the load of the structure. In addition, for the shallow elements, the stress increments (Fig. 3c) are large enough to significantly alter the consolidation stress ratio, $\mathrm{K}_{c}$, which is the ratio of effective vertical to effective horizontal consolidation stresses $\left(K_{c}=\sigma_{1 c}^{\prime} / \sigma_{3 c}^{\prime}\right)$. $\quad K_{c}$ will generally be greater than 1.0 for shallow elements after the load placement irrespective of whether $K_{0}$ is greater than or less than 1.0. This may not be true for deeper soil elements, but is not of great concern from a practical point of view since the deeper elements may not contribute substantially to the overall performance of the foundation [20]. The $\mathrm{K}_{\mathrm{c}}$ vlaue is considered to be greater than 1.0 for the present discussion. 


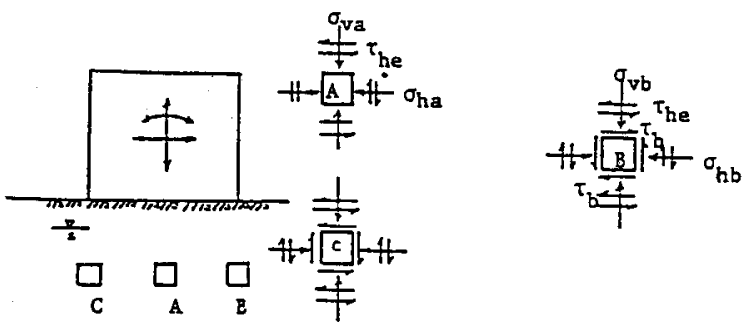

a) Geometry

b) Stresses on Soil Elements

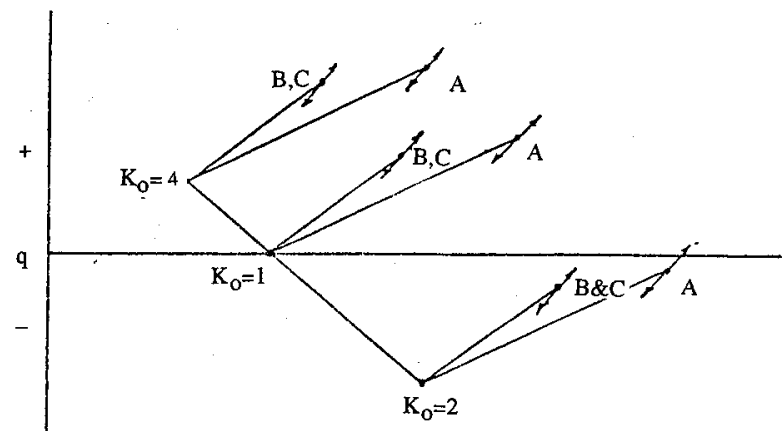

c) Stress Paths

Fig. 4. Foundation Stresses in Cyclic Loading Environments.

During an earthquake shaking, additional cyclic stresses will be produced in the soil elements. Fig. 4 illustrates the stress paths for the foundation soil elements under a structure subjected to cyclic loadings. The procedures for estimating these stress paths are:

1. Determine the likely and possible range of stresses existing in the field before the placement of the structure.

2. Determine a typical stress increase resulting from the weight of the structure.

3. Determine stresses induced in the foundation soil by the structure under the design earthquake conditions.

4. Superimpose the above stresses to give possible and likely foundation stress states during earthquake loadings.

Laboratory simulation of loading conditions of an in situ soil element under cyclic compression condition (i.e. the effective vertical stress is always greater than the effective horizontal stress before the cyclic loading is applied) requires that samples be consolidated anisotropically with effective vertical to horizontal stress ratio, $\sigma_{1 \mathrm{c}}^{\prime} / \sigma_{3 \mathrm{c}}^{\prime}$, being exactly equal to $K_{\mathrm{c}}$. The value of $\mathrm{K}_{\mathrm{c}}$ significantly influences the cyclic strength of aniso-

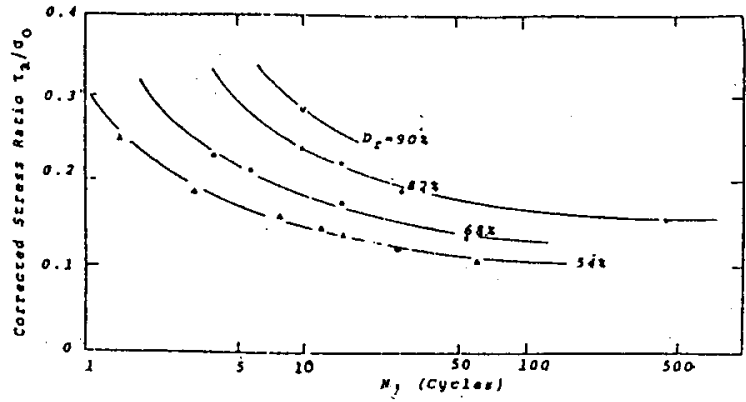

Fig. 5. Corrected $\tau_{a} / \sigma_{0}^{\prime}$ vs. $\mathrm{N}_{\ell}$ for Initial Liquefaction [4].

tropic soils and needs to be considered appropriately in any model.

Since an anisotropically consolidated sample can fail during the cyclic loading before the pore-water pressure reaches the confining pressure $[14,19]$, the load cycles required to cause pore pressure equal to the confining pressure cannot be used as a parameter in the model of anisotropic shear strength. A parameter related to the load cycles required to cause pore pressure to reach a defined failure criterion other than the confining pressure must be considered. In the past, many researchers [11] discussed the appropriateness of defining the failure criterion as a function of the amount of vertical strain of the anisotropically consolidated soil specimens during the cyclic loading. For example, Lee and Seed [14] stated that for anisotropic tests, "The most useful failure critetion would be the development of a predetermined compressive axial strain." However, due to lack of data, a specific failure criterion in terms of vertical strain has yet to be established. Chang et al [1] also proposed a failure criterion. According to them, a specimen will be considered to have failed if the accumulated pore pressure build-up reaches the limiting value of residual pore pressure, $u_{f}$, that can possibly occur in a sample for a given $K_{c}$ vlaue. This failure criterion is considered in this study, and will be discussed in the following sections. The number of cycles of a given magnitude of applied cyclic shear stress required to cause pore pressure build-up of $u_{f}$ will be used as a parameter in the analyses of anisotropic cyclic shear strength, and other liquefaction characteristics .

\section{PROPOSED METHODOLOGY}

Cyclic shear strength of a sand deposit has been studied by many researchers as discussed in previous section. In their studies, cyclic shear strength is usually expressed by family of curves relating cyclic shear stress ratio $S R$ and cycles required to cause a defined failure criterion under various confining pressures $\sigma_{3}^{\prime}$, relative densities $D_{r}$, or axial strain, as shown in Fig. 5 [4]. However, just few of them [3,9] have presented a mathematical model to express the relationship be- 


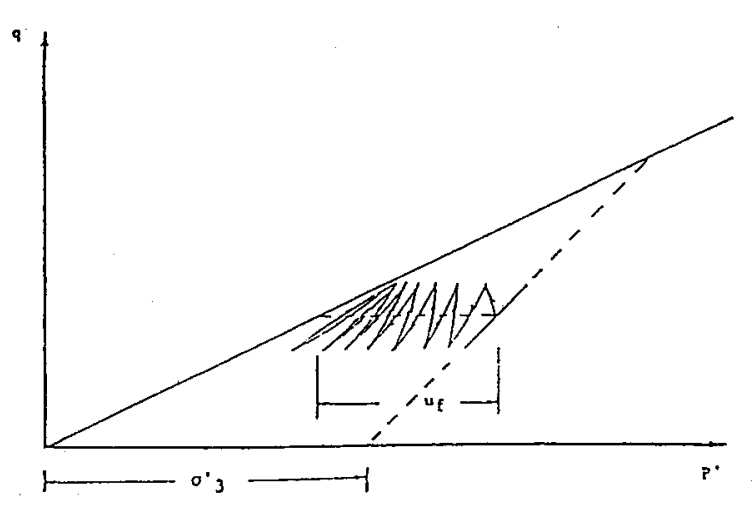

Fig. 6. Effective Stress Paths under Cyclic Loading.

tween the cycic strength and $S R, \sigma_{3}^{\prime}$ and $D_{r}$. With a mathematical model, the shear strength of a sand deposit can easily be calculated considering all the factors involved without reading many related figures. In here, a mathematical model is initiated by one of the author [3] and is discussed in this section.

\subsection{Pore Pressure Generation Model}

Based on the observation of the rate of pore pressure development in either cyclic triaxial or simple shear tests, Seed et al. [18] proposed a functional relationship between the pore pressure ratio, $r_{u}$, the shear stress ratio, $\mathrm{SR}$, and the normalized number of cycles $\mathrm{K}_{\mathrm{N}}$ of the form:

$$
r_{u}=\frac{1}{2}+\frac{1}{\pi} \sin ^{-1}\left(2 r_{N}^{1 / \theta}-1\right)
$$

where $\theta=\mathrm{a}$ function of the soil properties and the stress ratios $S R ; r=N / N_{l}$; the ratio of equivalent uniform cycles $\mathbf{N}$ to the number of uniform stress cycles required to produce a condition of initial liquefaction under undrained conditions $\mathbf{N}_{\ell}$.

Seed et al. [18] chose a unique curve with $\theta=0.7$ as an average representative of different soil properties and test conditions. The model Seed et al. proposed is a popular formula for the prediction of pore water pressure generation. However, Seed's model is applicable only for foundation soil below level ground that is very often assumed to be initially under hydrostatic stress or isotropic stress conditions.

To overcome above mentioned limitation, Finn et al. [7] developed a model for prediction of pore water pressure in anisotropically consolidated specimen, under cyclic triaxial loading in the laboratory. However, Finn's method defining pore pressure reaches 50 percent of the confining pressure as the failure criterion, that appears to be satisfactory only for low values of consolidation stress reaio $K_{c}$, not applicable to a high value of consolidation stress ratio.
For cyclic compression test conditions, where stress reversal does not occur, the maximum pore pressure at the end of cycling that can develop is equal to the horizontal distance $u_{f}$ from the stress point with coordinae $\left(p^{\prime}, q\right)$ to the failure line as shown in Fig.6, and is given by:

$$
\begin{aligned}
& u_{f}=p^{\prime}-q / \sin \Phi^{\prime} \\
= & \sigma_{1}^{\prime}\left[\frac{K_{c}\left(1+\sin \Phi^{\prime}\right)}{2 \sin \Phi^{\prime}}-\frac{\left(1-\sin \Phi^{\prime}\right)}{2 \sin \Phi^{\prime}}\right]
\end{aligned}
$$

where $\mathrm{p}^{\prime}=$ mean effective consolidation stress = $\left(\sigma_{1}^{\prime}+\sigma_{3}^{\prime}\right) / 2 ; \mathrm{q}=$ mean deviatic stress $=\left(\sigma_{1}^{-}+\sigma_{3}^{\prime}\right) / 2$; and $\Phi^{\prime}=$ angle of internal friction. Eq. 2 is also applicable to isotropic conditions. For isotropic conditions, $K_{\varepsilon}=1$ and $\mathrm{u}_{f}=\sigma_{3}^{\prime}$. When the shear stress reversal occurs, the pore pressure building up may reach confining pressure, and $\mathrm{u}_{f}$ vlaue may equal $\sigma_{3}^{\prime}$.

\subsection{Cyclic Soil Strength Evaluation Model}

For shear strength analysis for level ground conditions, Haldar and Miller [10] introduced a nondimentional soil strength parameter to represent soil resistance aganist liquefaction. They presented a relationship between the soil strength parameter and the number of cycles needed to cause liquefaction under isotropic stress conditions. However, Haldar et al. defined the failure criterion as pore water pressure reaches the confining pressure. Their model is available only for level ground or isotropic condition. Since consolidation stress ratio $K_{c}$ has a significant effect on shear strength, Haldar's model needs to be modified to satisfy also the anisotorpically consolidated conditions.

To develop a general model in the shear strength analysis that is available for both isotropic and anisotropic conditions, a nondimentional soil strength parameter, $\mathbf{R}$, that is similar to Haldar and Miller's cyclic shear strength parameter under level ground condidions, is introduced here to represent soil resistance against earthquake induced cyclic stresses. A relationship between $\mathrm{R}$ and the number of cycles $\mathrm{N}_{f}$ needed to cause failure is presented. The cyclic shear strength parameter, $R$, is definded as [3] :

$$
R=\left(\tau_{a} / p^{\prime}\right)\left(1 / 2 D_{r}\right)=S R\left(1 / 2 D_{r}\right)
$$

where $\tau_{a}=$ cyclic shear stress; $D_{r}=$ relative density; $S R=$. cyclic stress ratio $;$ and $p^{\prime}=$ average effective stress.

A large amounts of cyclic undrained triaxial tests using Taichung and Maoli coast sands are conducted by the authors. The physical properties of these two sands are presetned in Table 1, while the test results are listed in Table 2. As shown in Table 1, Taichung coast sand 
Table 1. Physical Properties of Sand Specimen [3]

\begin{tabular}{lcccccc}
\hline & Fine Content & $\mathrm{d}_{50}$ & $\mathrm{Cu}$ & $\mathrm{Gs}$ & $\mathrm{Y}_{\max }$ & $\mathrm{Y}_{\min }$ \\
\hline Maoli Sand & $(\%)$ & $(\mathrm{mm})$ & & & $(\mathrm{g} / \mathrm{cm})$ & $(\mathrm{g} / \mathrm{cm})$ \\
Taichung Sa. & 3.5 & 0.25 & 2.0 & 2.62 & 1.669 & 1.361 \\
& 0.9 & 0.19 & 1.8 & 2.70 & 1.615 & 1.325 \\
\hline
\end{tabular}

Table 2. Soil Properties and Undrained Cycilic Test Results [3]

\begin{tabular}{|c|c|c|c|c|c|c|c|c|c|}
\hline & $\mathrm{D}_{\mathrm{r}}$ & $\phi^{\prime}$ & $\mathbf{K}_{\mathbf{C}}$ & $\begin{array}{c}\tau_{\mathrm{a}} \\
(\mathrm{kPa})\end{array}$ & $\begin{array}{c}\mathrm{SR} \\
\left(\tau_{\mathrm{a}} / \mathrm{P}_{0}{ }^{\prime}\right)\end{array}$ & $\mathbf{R}$ & $\mathrm{u}_{f} / \sigma_{3}^{\prime}$ & $\mathrm{N}$ & $\begin{array}{c}\sigma_{\mathrm{a}}^{\prime} \\
(\mathrm{kPa})\end{array}$ \\
\hline TYA5 & 0.41 & 29 & 1 & 25 & 0.25 & 0.305 & 1.0 & 5 & 100 \\
\hline TYA11 & 0.57 & 30.6 & 1 & 26 & 0.26 & 0.228 & 1.0 & 27 & 100 \\
\hline TYA14 & 0.57 & 30.6 & 1 & 28 & 0.28 & 0.246 & 1.0 & 19 & 100 \\
\hline TYA15 & 0.57 & 30.6 & 1 & 24 & 0.24 & 0.211 & 1.0 & 58 & 100 \\
\hline YTA17 & 0.77 & 33.4 & 1 & 36 & 0.36 & 0.234 & 1.0 & 17 & 100 \\
\hline TYA19 & 0.77 & 33.4 & 1 & 34 & 0.34 & 0.221 & 1.0 & 30 & 100 \\
\hline TYA20 & 0.77 & 33.4 & 1 & 38 & 0.38 & 0.247 & 1.0 & 14 & 100 \\
\hline TYA21 & 0.59 & 30.6 & 1 & 65 & 0.26 & 0.22 & 1.0 & 9 & 250 \\
\hline TYA23 & 0.59 & 30.6 & 1 & 55 & 0.22 & 0.186 & 1.0 & 25 & 250 \\
\hline TYA24 & 0.59 & 30.6 & 1 & 50 & 0.2 & 0.169 & 1.0 & 57 & 250 \\
\hline TYA9 & 0.44 & 29 & 1 & 50 & 0.25 & 0.284 & 1.0 & 4 & 200 \\
\hline TYA50 & 0.463 & 29 & 0.6 & 50 & 0.25 & 0.27 & 0.646 & 6 & 250 \\
\hline TYA43 & 0.466 & 29 & 0.8 & 50 & 0.222 & 0.238 & 0.867 & 19 & 250 \\
\hline TYA44 & 0.466 & 29 & 0.8 & 45 & 0.2 & 0.215 & 0.867 & 81 & 250 \\
\hline TYA47 & 0.757 & 33.4 & 0.8 & 55 & 0.244 & 0.161 & 0.898 & 76 & 250 \\
\hline TYA52 & 0.463 & 29 & 0.6 & 55 & 0.275 & 0.297 & 0.646 & 6 & 250 \\
\hline TYA55 & 0.757 & 33.4 & 0.8 & 60 & 0.267 & 0.176 & 0.898 & 38 & 250 \\
\hline TYA59 & 0.618 & 30.6 & 0.6 & 65 & 0.325 & 0.263 & 0.679 & 6 & 250 \\
\hline TYA60 & 0.751 & 33.4 & 0.6 & 75 & 0.375 & 0.25 & 0.728 & 10 & 250 \\
\hline TYA65 & 0.751 & 33.4 & 0.6 & 67.5 & 0.338 & 0.225 & 0.728 & 28 & 250 \\
\hline TYA74 & 0.624 & 30.6 & 0.8 & 50 & 0.222 & 0.178 & 0.879 & 113 & 250 \\
\hline TYA75 & 0.624 & 30.6 & 0.8 & 55 & 0.244 & 0.196 & 0.879 & 26 & 250 \\
\hline TYA77 & 0.616 & 30.6 & 0.7 & 60 & 0.282 & 0.229 & 0.793 & 43 & 250 \\
\hline TYA81 & 0.748 & 33.4 & 0.7 & 62.5 & 0.294 & 0.197 & 0.825 & 71 & 250 \\
\hline TYA85 & 0.748 & 33.4 & 0.7 & 67.5 & 0.318 & 0.213 & 0.825 & 13 & 250 \\
\hline TYA86 & 0.616 & 30.6 & 0.7 & 63 & 0.296 & 0.24 & 0.793 & 10 & 250 \\
\hline TYB9 & 0.43 & 30.6 & 1 & 22.5 & 0.225 & $0.253^{*}$ & 1.0 & 83 & 100 \\
\hline TYB12 & 0.62 & 33.1 & 1 & 26 & 0.26 & $0.202 *$ & 1.0 & 67 & 100 \\
\hline TYB15 & 0.62 & 33.1 & 1 & 34 & 0.34 & $0.264^{*}$ & 1.0 & 29 & 100 \\
\hline TYB23 & 0.462 & 30.6 & 0.8 & 45 & 0.2 & $0.208^{*}$ & 0.879 & 21 & 250 \\
\hline TYB24 & 0.462 & 30.6 & 0.8 & 41 & 0.182 & $0.190 *$ & 0.879 & 49 & 250 \\
\hline TYB25 & 0.462 & 30.6 & 0.6 & 54 & 0.27 & $0.282^{*}$ & 0.679 & 8 & 250 \\
\hline TYB26 & 0.462 & 30.6 & 0.6 & 58 & 0.29 & $0.303^{*}$ & 0.679 & 5 & 250 \\
\hline TYB27 & 0.653 & 33.1 & 0.8 & 53 & 0.236 & $0.174^{*}$ & 0.896 & 23 & 250 \\
\hline TYB30 & 0.646 & 33.1 & 0.6 & 65 & 0.325 & 0.243 & 0.723 & 7 & 250 \\
\hline TYB31 & 0.646 & 33.1 & 0.6 & 60 & 0.3 & $0.224^{*}$ & 0.723 & 45 & 250 \\
\hline
\end{tabular}




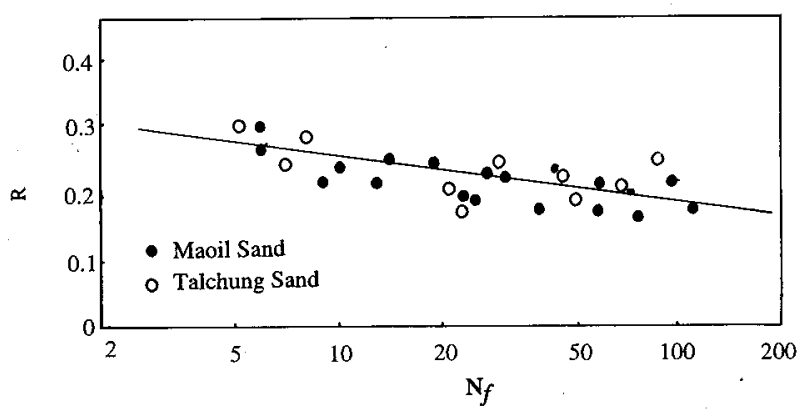

Fig. 7. The Relationship between $\mathbf{R}$ and $\mathbf{N}_{f}$.

has different mean grain size $(0.19 \mathrm{~mm})$ from Maoli sand $(0.25 \mathrm{~mm})$. Since the cyclic strength of a saturated sand deposit can be affected by the soil particle, represented in this study by the mean grain size, $d_{50}$, the cyclic shear strength parameter obtained in Taichung by using Eq.3 must be modified for Maoli sand by introducing a corrective factor. If the relationship is normalized to Maoli sand with $d_{50}$ being eaual to $0.25 \mathrm{~mm}$, the cyclic shear strength parameter obtained by using Eq. 3 can be illustrated in Fig. 7 aganist corresponding $N_{f}$ value.

A regression analysis is performed on the data of Fig. 7 and the following regression equation results [3]:

$$
R=0.3221-0.0304 \ln (N)
$$

The $r^{2}$ value of regression is found to be 0.6 , that shows the predictibability of Eq.4 is expected to be good.

\section{APPLICATION FOR EVALUATION OF CYCLIC CHARACTERISTICS}

\subsection{Evaluation of $\mathbf{N}_{\ell}\left(\right.$ or $\left.\mathbf{N}_{f}\right)$}

The number of cycles, $N_{\ell}$, required to produce a condition of initial liquefaction in the level ground sand layer (or $\mathrm{N}_{f}$ for anisotropic condition) is generally obtained from cyclic test results. It may be read directly from a family of curves established by cyclic tests such as that shown in Fig.5. However, to establish such a family of curves, one has to perform a series of complex and time consuming cyclic tests. Actually, the $\mathrm{N}_{\ell}$ or $\mathrm{N}_{f}$ value can easily be obtained by the mathematical model developed in this study. By inversing Eq.4, $\mathrm{N}_{\ell}$ or $\mathrm{N}_{f}$ value is expressed as :

$$
\mathrm{N}_{f}=\exp \left(\frac{0.3221-R}{0.0304}\right.
$$

in which $R$ is defined in Eq.3, i.e. $R=S R\left(1 / 2 D_{r}\right)$. Therefore, once earthquake induced stress ratio $S R$ and sand relative density $D_{r}$ are known, the number of cycles required to produce defined failure condition can easily
Table 3. Eathquake Magnitude and Corresponding Value of $\mathbf{N}_{\mathrm{eq}}$ and Shaking Duration [7]

\begin{tabular}{ccc}
\hline $\begin{array}{c}\text { Earthquake } \\
\text { Magnitude } \\
\mathrm{M}\end{array}$ & $\mathrm{N}_{\text {eq }}$ & $\begin{array}{c}\text { Duration of Strong } \\
\text { Shaking, } \mathrm{t}_{\mathrm{d}} \text { (second) }\end{array}$ \\
\hline $5.5-6$ & 5 & 8 \\
6.5 & 8 & 14 \\
7.0 & 10 & 20 \\
7.5 & 20 & 40 \\
8.0 & 30 & 60 \\
\hline
\end{tabular}

be calculated from Eq.5.

\subsection{Evaluation of Cyclic Shear Strength}

If the number of stress cycles $\mathrm{N}$ induced during an earthquake is known, the cyclic shear strength can indiredtly be calculated from Eq.4, that is :

$$
R=0.3221-0.0304 \ln (\mathrm{N})
$$

in which $R$ is defined in Eq.3,

$$
R=\operatorname{SR}\left(1 / 2 D_{r}\right)=\left(\tau / p^{\prime}\right)\left(1 / 2 D_{r}\right)
$$

Therefore,

$$
\tau_{R}=\left(2 D_{r} p^{\prime}\right)[0.3221-0.0304 \ln (N)]
$$

In his research, Housner[12] found that the value of the number of cyclic stress induced during an earthquake depends on the duration of ground shaking and thus on the magnitude of the earthquake. Based on Housner conclusion, Seed and Idriss [17] proposed approximate equivalent number of stress cycles $N_{\mathrm{eq}}$ corresponding to the earthquake magnitude and shaking durations as shown in Table 3. For convenience of numerical application, Haldar [8] proprsed a relationship between $\mathrm{N}_{\mathrm{eq}}$ and earthquake magnitude $\mathrm{M}$ expressed in Ritcher's scale. The relationship is represented as :

$$
\mathrm{N}_{\mathrm{eq}}=106.08-36.42 \mathrm{M}+3.312 \mathrm{M}^{2}
$$

Once the number of equivalent stress cycles induced by an earthquake of magnitude $M$, the soil relative $\mathrm{P}$, and average effective stress $\mathrm{p}^{\prime}$ are known, one can easily calculate soil cyclic shear strength by using Eq.6.

\subsection{Evaluation of Pore Water Pressure}

Prior to estimate numerically the pore water pressure build-up, the normalized number of cycles must be estimated. $r_{N}$ is the ratio of number of earthquake 
induced equivalent stress cycles $\mathrm{N}_{\mathrm{eq}}$ to the number required to cause liquefaction or failure condition $\mathrm{N}_{\ell}$ (or $\mathrm{N}_{f}$ ). $\mathrm{N}_{\mathrm{eq}}$ can be obtained in Eq. 7, while $\mathrm{N}_{f}$ (or $\mathrm{N}_{\ell}$ ) can be estimated in Eq. 5, then the accumulated pore water pressure ratio $r_{u}$ after the application of earthquake induced $\mathrm{N}_{\mathrm{eq}}$ stress cycles can easily be calculated from Eq.1. Consequently, the excess pore water pressure $u_{\mathrm{g}}$ can easily be predicted .

\section{ILLUSTRATION}

In order to evaluate liquefaction characteristics of soil deposit at a site, steps involved for evaluation are illustrated with the help of an example. A site in Niigate, Japan, which liquefied during the 1964 earthquake is considered here. The magnitude of the earthquake was $M=7.5$ and the site experienced an estimated $0.16 \mathrm{~g}$ maximum ground acceleration [17]. The depth of the water table was $3 \mathrm{ft}$. from the ground surface. The saturated unit weight $\gamma_{\mathrm{s}}$ and the relative density $\mathrm{D}_{\mathrm{r}}$, were considered to be 120 pcf and 0.5 , respectively. The following summarized the steps in the computation procedure for evaluation of liquefaction characteristics for soil element at depth $\mathrm{h}=25 \mathrm{ft}$ from ground surface.

\subsection{Evaluation of $\mathbf{N}_{\mathfrak{l}}$}

(i) total vertical stress, $\sigma_{v}$

$$
\sigma_{v}=\gamma_{s} h=120(25)=3000 \mathrm{psf}
$$

(ii) effective vertical stress, $\sigma_{v}^{\prime}$

$$
\sigma_{\mathrm{v}}^{\prime}=120(25)-62.4(25-3)=1627.2 \mathrm{psf}
$$

(iii) assume coefficient of earth pressure at rest, $\mathrm{K}_{6}=0.45$

$$
\mathrm{p}^{\prime}=\sigma_{\mathrm{v}}^{\prime}(1+0.45) / 2=1179.7 \mathrm{psf}
$$

(iv) earthquake induced shear stress, $\tau_{a}[17]$

$\tau_{a}=0.65 \sigma_{\mathrm{v}}\left(a_{\max } / \mathrm{g}\right)=0.65(3000)(0.16)(0.948)=295.7 \mathrm{psf}$

where $r_{d}=a$ stress reduction factor, for $h=25 f t, r_{d}=0.948$ $[8,17]$

(v) strength parameter $R$

$R=\left(\tau_{\mathrm{a}} / \mathrm{p}^{\prime}\right)\left(1 / 2 \mathrm{D}_{\mathrm{r}}\right)=\frac{295.7}{(1179.7)(2)(0.5)}=0.2506$

(vi) cycles needed to induce liquefaction, $\mathrm{N}_{\ell}$

$\mathrm{N}_{\ell}=\exp \left(\frac{0.3221-\mathrm{R}}{0.0304}\right)=\exp \left(\frac{0.3221-0.2506}{0.0304}\right)=10.5$

\subsection{Evaluation of $\tau_{R}$ and Liquefaction Potential}

(i) earthquake induced equivalent cycles $\mathrm{N}_{\mathrm{eq}}$

$$
\mathrm{N}_{\mathrm{eq}}=106.08-36.42 \mathrm{M}+3.312 \mathrm{M} 3=19.23
$$

Note that $N_{e q}(=19.23)>N_{\ell}(=10.5)$, implies that it be liquefied.

(ii) shear resistance, $\tau_{R}$

$$
\begin{aligned}
\tau_{R} & =2 D_{r}\left(p^{\prime}\right)\left[0.3221-0.0304 \ln \left(N_{e q}\right)\right] \\
& =2(0.5)(1179.7)[0.3221-0.0304 \ln (19.23)] \\
& =273.95 \mathrm{psf}
\end{aligned}
$$

(iii) liquefaction evaluation

$$
\tau_{R}(=273.95 \mathrm{psf})<\tau_{a}(=295.7 \mathrm{psf})
$$

Therefore, it is liquefied.

\subsection{Evaluation of Pore Water Pressure, $\mathbf{u}_{\mathrm{g}}$}

(i) $\mathrm{r}_{\mathrm{N}}=\mathrm{N}_{\mathrm{eq}} / \mathrm{N}_{\mathrm{l}}=19.23 / 10.5=1.83>1$, take $\mathrm{r}_{\mathrm{N}}=1$

(ii) $r_{u}=\frac{1}{2}+\frac{1}{\pi} \sin ^{-1}\left(2 N_{N}^{1 / \theta}-1\right)=1$

There, $u_{g}=\sigma_{v}^{\prime}=1627.2 \mathrm{psf}$

\section{CONCLUSION}

A mathematical model is proposed here to estimate the cyclic characteristics of a soil deposit subjected to earthquake loading. Cyclic triaxial test results are used to develop the basic model. Using this basic model and common used soil's physical properties, the cyclic shear strength $\tau_{R}$, the number of cycles required to cause liquefaction $\mathrm{N}_{\ell}$, or failure condition $\mathrm{N}_{f}$, and the generation of excess pore water pressure $u_{\mathrm{g}}$ can easily be evaluated. Thus in engineering application it can avoid complex laboratory cyclic test and save a lot of time.

\section{REFERENCES}

1. Chang, C.S., Kuo, C.L., and Selig, E.T., "Pore Pressure Development During Cyclic Loading," J. of Geot. Engr. Division, ASCE, Vol. 109, No. GT1, Jan., 1983, pp. 103-107.

2. Chern, S., "Probabilistic Analysis of Pore Pressure Induced Damaged Potential for Structures Subjected to Earthquake Motions, Ph. D. Theisi, Georgia Institute of Technology, Georgia, 1986.

3. Chern, S., "Cyclic Sear Strength of Sand in Offshore Environment," Chinese J. of Mechanics, Vol. 7, No. 2, June, 1991, pp. 1-10. 
4. De Alkba, P., Chan, C.K., and Seed, H.B., "Determination of Soil Liquefaction Characteristics by Large-Scale Laboratory Tests," Earthquake Engr. Research Center Report No. EERC 75-14, Univ. of Cal., Berkeley, 1975.

5. Finn, W. D. L., Emery, J.J., and Gupta, Y.P., “A Shake Table Study of the Liquefaction of Saturated Sands during Earthquake," Proc., 3rd European Symp. on Earthquake Engr., 1970, pp. 253-262.

6. Finn, W.D.L., Pickering, D.T., and Bransby, P.L., "Sand Liquefaction in Triaxial and Simple Shear Tests," J. of Soil Mechanics and Foundations Division, ASCE, Vol. 97, No. SM4, Apr.. 1971, pp. 639659.

7. Finn, W.D.L., and Bhatia, S.K., "Prediction of Seismic Pore-Water Pressure," Proceedings, 10th International Conf. on S.M. and Foundation Engr., Stockholm, June, 1981, pp. 201-206.

8. Haldar, A., "Probabilistic Evaluation of Liquefaction of Sand under Earthquake Motions," Ph. D. Thesis, Univ. of Ill., Urbana, Ill.,1976.

9. Haldar, A., and Tang, W.H., "Statistical Study of Uniform Cycles in Earthquake Motions," J. of Geot. Engr. Division, ASCE, Vol. 107, No. GT5, May, 1981, pp. 577-589.

10. Haldar, A., and Miller, F.J., "Statistical Evaluation of Cyclic Strength of Sand," J. of Geot. Engr. Division, ASCE, Vol. 110, No. 12, Dec., 1984, pp. 17851802.

11. Hedberg, J., "Cyclic Stress-Strain Behavior of Sand in Offshore Environment," Ph. D. Thesis, Mass. Institute of Technology, Mass, 1977.

12. Housner, G.W., "Intensity of Ground Shaking Near the Causative Fault," Proceedings, 3rd World Conf. on Earthquake Engr., Vol. 1, New England, 1965.
13. Ishibashi, I., and Sherif, M.A., "Soil Liquefaction by Torsional Simple Shear Device,"J. of Geotechnical Engr. Division, ASCE, Vol. 100, No. GT8, Ang., 1974, pp. 871-888.

14. Lee, K.L. and Seed, H.B., "Dynamic Strength of Anisotropically Consolidated Sand," J. of S. M. and Foundations Division, ASCE, Vol. 93, No. SM5, Sep., 1967, pp. 169-190.

15. Oshaki, Y., "Effects of Sand Compaction on Liquefaction During the Jokachioki Earthquake," Soils and Foundations, Vol. 10, No. 2, June, 1970, pp. 112128.

16. Peacock, W.H., and Seed, H.B., "Sand Liquefaction under Cyclic Loading Simple Shear Conditions," J. of Soil Mechanics and Foundation Division, ASCE, Vol. 94, No. SM3, May, 1968, pp. 689-708.

17. Seed, H.B., and Idriss, I.M., "Simplified Procedure for Evaluation Soil Liquefaction Potential," J. of S.M. and Foundation Division, ASCE, Vol. 97, No. SM9, Sep., 1974, pp. 1249-1273.

18. Seed, H.B., Martin, P.P., and Lysmer, J., "Pore Water Pressure Chnages During Soil Liquefaction," J. of Geot. Engr. Division, ASCE, Vol. 102, No. GT4, 1976.

19. Selig, E.T. and Chang, C.S., "Soil Failure Modes in Undrained Cyclic Loading," J. of Geotechnical Engr. Division, ASEC, Vol. 107, No. GT5, May, 1981, pp. 539-551.

20. Urzua, A., "Analysis of permanent Displacement from Cyclic Loading of Foundations," Ph. D. Thesis, Mass. Institute of Technology, Mass, 1981.

21. Youd, T.L., and Bennett, M.J., "Liquefaction Sites, Imperial Valley, California, J. of Geot. Engr. Division, ASCE, Vol. 109, No. 3, March, 1983, pp. 440-457. 